\title{
0032. Relationship between microcirculatory alterations and venous-to-arterial carbon dioxide differences in patients with septic shock
}

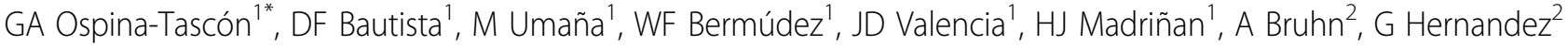 \\ , M Granados', CA Arango-Dávila', D De Backer ${ }^{3}$
}

From ESICM LIVES 2014

Barcelona, Spain. 27 September - 1 October 2014

\section{Introduction}

Increased venous to arterial carbon dioxide difference $\left(\mathrm{Pv}-\mathrm{aCO}{ }_{2}\right)$ have been attributed to low cardiac output states. However, mechanisms conducting to $\mathrm{Pv}-\mathrm{aCO}_{2}$ increases during normal or even high cardiac output conditions as in septic shock are not fully understood. We hypothesized that $\mathrm{Pv}-\mathrm{aCO}{ }_{2}$ could reflect the adequacy of microvascular perfusion during resuscitated septic shock

\section{Objectives}

To test the hypothesis that $\mathrm{Pv}-\mathrm{aCO}_{2}$ could reflect the microvascular blood flow during the early phases of resuscitation in septic shock

\section{Methods}

We included 80 patients with a first episode of septic shock admitted to a mixed ICU in a University Hospital over a 12-month period. Time 0 (T0) was set at ICU admission when a pulmonary artery catheter was inserted. Arterial and venous gases analyses were performed at T0 and 6 hours after (T6). We defined $\mathrm{Pv}-\mathrm{aCO}{ }_{2}$ as the difference between the mixed venous and arterial $\mathrm{CO}_{2}$ partial pressures. A Sidestream Dark-Field (SDF) imaging device (Microvision Medical, Amsterdam, the Netherlands) was used to evaluate the sublingual microcirculation both at T0 and T6. At each assessment, 5 sequences of 20 seconds each were recorded and stored under a random number. An investigator blinded to the sequence order and patient's clinical course, analyzed the sequences semi-quantitatively. The vessels were separated into large and small using a cut-off value of $20 \mu \mathrm{m}$ in diameter. We evaluated the relation between the percentage of small vessels perfused and the $\mathrm{Pv}-\mathrm{aCO}_{2}$ using linear and non-linear regressions and Spearman Rho test. A $p<0.05$ was considered as significant.

\section{Results}

We found significant but very weak relationships between general hemodynamics or oxygen derived parameters with $\mathrm{Pv}-\mathrm{CO}_{2} \cdot \mathrm{Pv}-\mathrm{aCO} \mathrm{C}_{2}$ was inversely related to the percentage of small vessels perfused both at $\mathrm{T} 0$ and T6 (T0: $\mathrm{R}^{2}: 0.515, \mathrm{p}<0.001 ;$ T6: $\mathrm{R}^{2}: 0.453, \mathrm{p}<0.001$ ).

\section{Conclusions}

Microvascular blood flow is a key determinant of $\mathrm{Pv}-\mathrm{aCO} 2$ during normodynamic septic shock. $\mathrm{Pv}_{2} \mathrm{aCO} \mathrm{O}_{2}$ could track microvascular alterations during early phases of septic shock. 


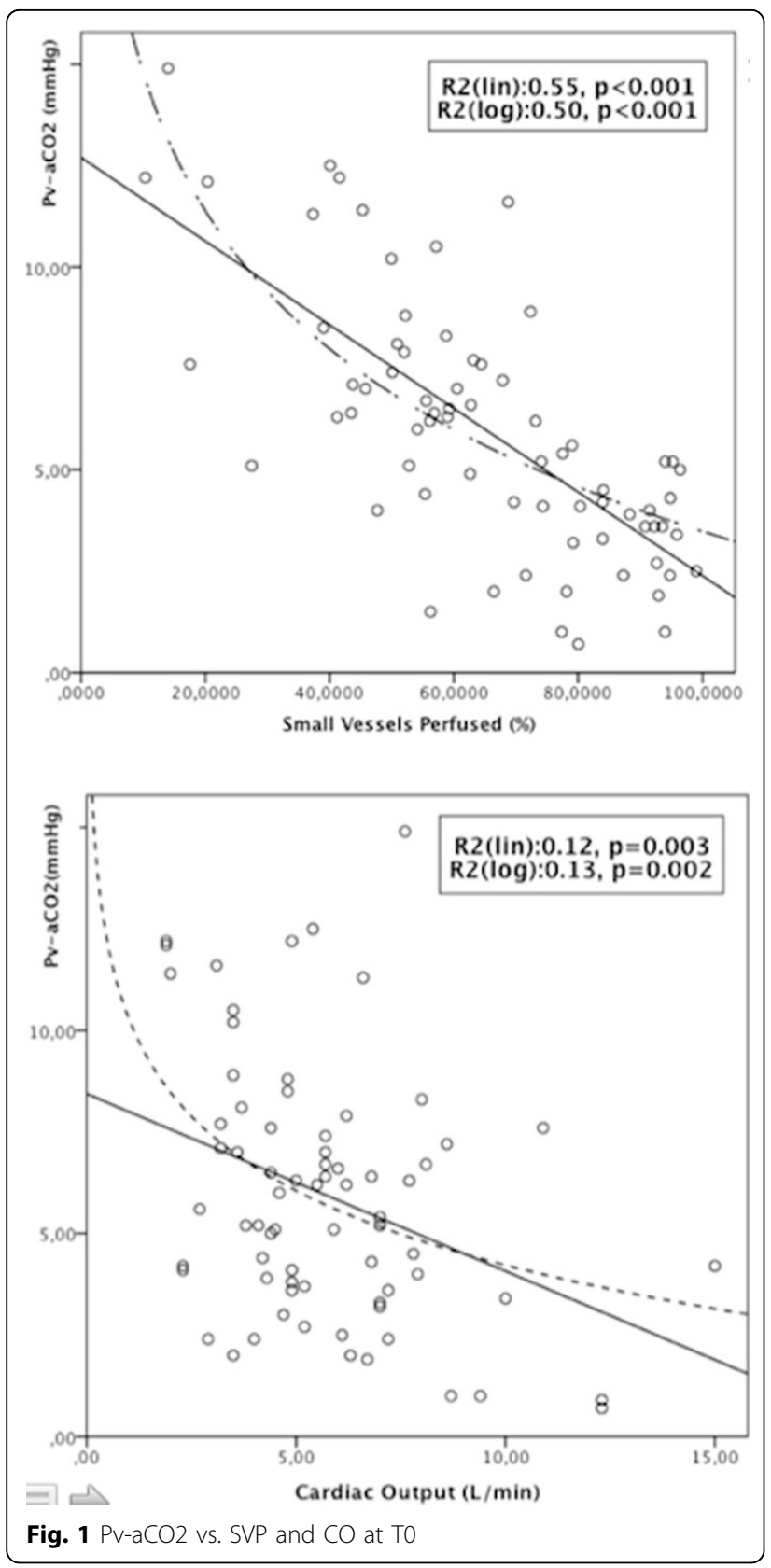

Table 1 General hemodynamics and Oxygen-derived parameters

\begin{tabular}{lll}
\hline & T0 & T6 \\
\hline SvO2, (\%) & $68.8(61.75-75.0)$ & $69.7(64.4-75.9)$ \\
\hline Cardiac Index, (L/min/m2) & $3.3(2.4-4.0)$ & $3.2(2.7-3.8)$ \\
\hline $\mathrm{iDO} 2,(\mathrm{ml} / \mathrm{min} / \mathrm{m} 2)$ & $389.0(293.4-500.3)$ & $399.0(322.3-468.2)$ \\
\hline $\mathrm{iVO},(\mathrm{ml} / \mathrm{min} / \mathrm{m} 2)$ & $116.8(87.3-150.4)$ & $182.8(106.3-240.4)$ \\
\hline $\mathrm{PV}-\mathrm{aCO},(\mathrm{mmHg})$ & $5.2(3.6-7.2)$ & $5.8(3.5-7.7)$ \\
\hline
\end{tabular}
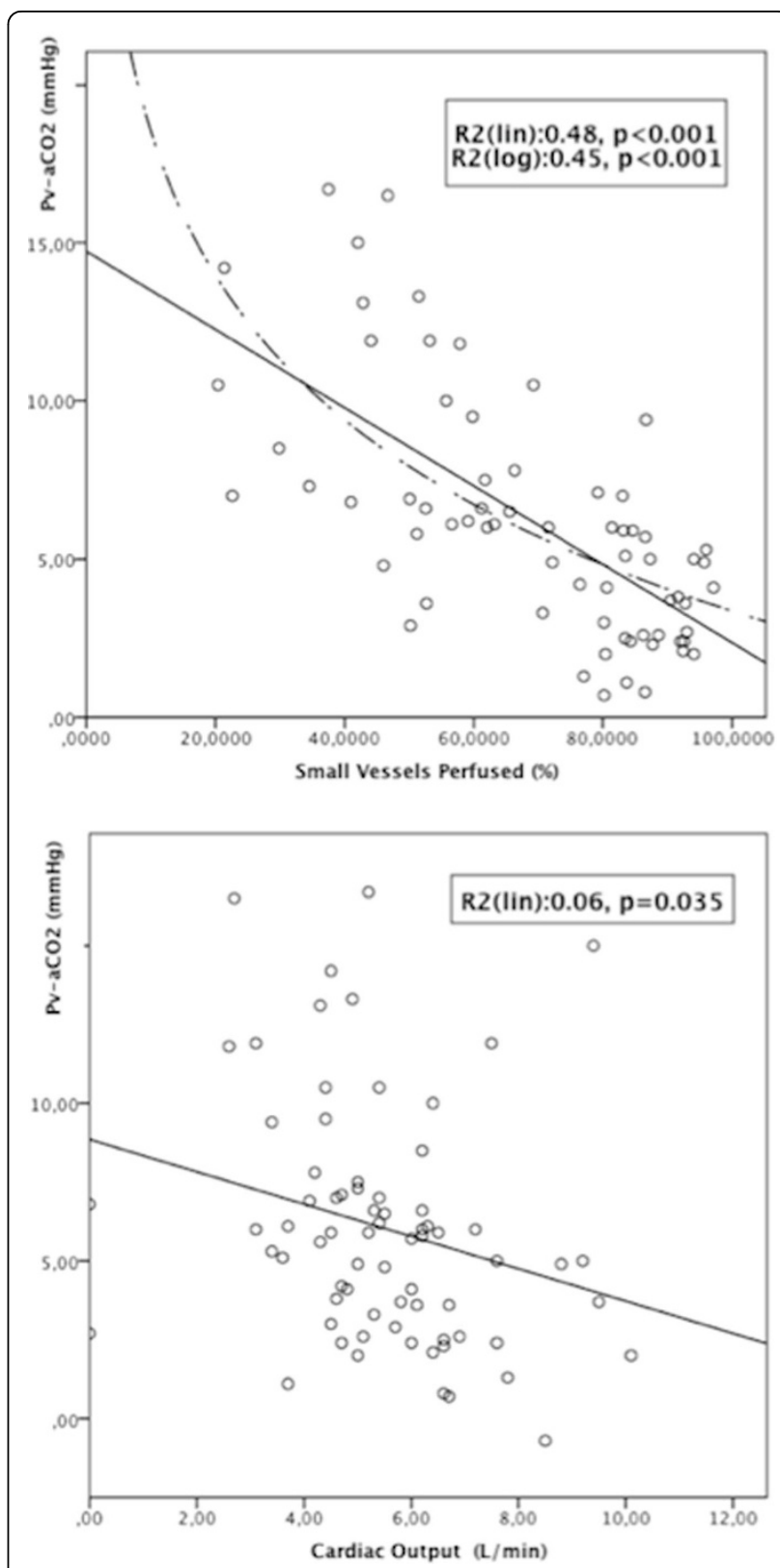

Fig. $2 \mathrm{Pv}-\mathrm{aCO} 2$ vs. SVP and CO at T6

\section{Authors' details}

'Fundación Valle del Lili, Universidad ICESI, Intensive Care Medicine Department, Cali, Colombia. ${ }^{2}$ Pontificia Universidad Católica de Chile, Facultad de Medicina, Departamento de Medicina Intensiva, Santiago, Chile. ${ }^{3}$ Free University of Brussels, Erasme Hospital, Intensive Care Medicine Department, Brussels, Belgium.

Published: 26 September 2014

doi:10.1186/2197-425X-2-S1-O5

Cite this article as: Ospina-Tascón et al:: 0032. Relationship between microcirculatory alterations and venous-to-arterial carbon dioxide differences in patients with septic shock. Intensive Care Medicine Experimental 2014 2(Suppl 1):O5. 